\title{
Ethinylestradiol Treatment Induces Multiple Canalicular Membrane Transport Alterations in Rat Liver
}

\author{
Roger Bossard, * * Bruno Stieger, * Brigitte O’Neill, * Gert Fricker, * and Peter J. Meier * \\ *Division of Clinical Pharmacology and Toxicology, Department of Medicine, University Hospital, Zurich, Switzerland; and \\ ${ }^{\ddagger}$ Laboratorium für Biochemie, Eidgenössische Technische Hochschule, Zurich, Switzerland
}

\begin{abstract}
We investigated the effects of $17 \alpha$-ethinylestradiol treatment of rats on various transport functions in isolated basolateral and canalicular liver plasma membrane vesicles. Both membrane subfractions were purified to a similar degree from control and cholestatic livers. Although moderate membrane lipid alterations were predominantly observed in basolateral vesicles, no change in basolateral $\mathrm{Na}^{+} / \mathrm{K}^{+}$-ATPase activity was found. Furthermore, while $\mathrm{Na}^{+}$-dependent taurocholate uptake was decreased by $\sim 40 \%$ in basolateral vesicles, the maximal velocity of ATP-dependent taurocholate transport was decreased by $63 \%$ in canalicular membranes. In contrast, only minimal changes or no changes at all were observed for electrogenic taurocholate transport in "cholestatic" canalicular membranes and total microsomes, respectively. However, canalicular vesicles from cholestatic livers also exhibited marked reductions in ATP-dependent transport of S-(2,4-dinitrophenyl)glutathione and in $\mathrm{Na}^{+}$-dependent uptake of adenosine, while in the same vesicles $\mathrm{HCO}_{3}^{-} / \mathrm{SO}_{4}^{-}$exchange and $\mathrm{Na}^{+} /$glycine cotransport activities were markedly stimulated. These data show that in addition to the previously demonstrated sinusoidal transport abnormalities ethinylestradiol-induced cholestasis is also associated with multiple canalicular membrane transport alterations in rat liver. Hence, functional transport alterations at both polar surface domains might ultimately be responsible for the inhibitory effects of estrogens on the organic anion excretory capacity and on bile formation in rat liver. (J. Clin. Invest. 1993. 91:2714-2720.) Key words: estrogens - cholestasis • membrane vesicles $\bullet$ bile acids $\bullet$ organic anions
\end{abstract}

\section{Introduction}

Estrogens are well known to cause reversible intrahepatic cholestasis in humans and animals. However, although estrogen-re-

Preliminary reports of this work have been presented at the biennial scientific meeting of the International Association for the Study of the Liver (IASL), Brighton, UK, June 1992, and at the European Association for the Study of the Liver (EASL), Vienna, August 1992, and published in abstract form (1992. Hepatology. 16:567, and 1992. J. Hepatol. [Amst.] 16:57.)

Dr. Fricker's present address is Pharma Development Department 507/305, Sandoz AG, CH-4002 Basel, Switzerland.

Address reprint requests to Peter J. Meier-Abt, M.D., Division of Clinical Pharmacology and Toxicology, Department of Medicine, University Hospital, $\mathrm{CH}-8091$ Zurich, Switzerland.

Received for publication 12 May 1992 and in revised form 3 December 1992.

J. Clin. Invest.

(c) The American Society for Clinical Investigation, Inc.

0021-9738/93/06/2714/07 \$2.00

Volume 91, June 1993, 2714-2720 lated cholestasis has now been of major clinical and experimental interest for nearly four decades, it is still unclear by what pathogenetic mechanism(s) natural and synthetic (e.g., 17 $\alpha$ ethinylestradiol [EE] $)^{1}$ estrogenic compounds interfere with hepatic bile formation (1-3). Thus, based on more recent observations neither an increased permeability of the paracellular pathway $(3,4)$ nor a decreased activity of the sinusoidal (or basolateral ) $\mathrm{Na}^{+} \mathrm{K}^{+}$-ATPase $(3,5,6)$ appears to be primary event in EE-induced cholestasis. Similarly, the pathophysiological significance of the demonstrated decrease in sinusoidal membrane fluidity $(6,7)$ remains uncertain, since decreased liver plasma membrane fluidity has been associated with both reduced and increased bile flow $(5,8)$. On the other hand, there is general agreement in all studies that EE treatment of rats leads to a decreased bile excretory capacity of the liver for a variety of organic anions including conjugated bile salts, bilirubin and sulfobromophthalein (BSP) $(1-3,9,10)$. Based on these observations it has been repeatedly suggested, but never directly tested, that an important cause of EE-induced cholestasis might be selective and/or multiple transport defects in the canalicular membrane of hepatocytes (1-3). This concept has been directly investigated in the present study using highly purified canalicular liver plasma membrane (cLPM) vesicles from control and EE-treated rats.

\section{Methods}

Animals and treatment. Male Sprague-Dawley rats (SUT:SDT, Süddeutsches Tierzuchtinstitut, Tutlingen, Germany) weighing 200$250 \mathrm{~g}$ were used throughout this study. The animals were housed in a constant temperature-humidity environment with alternating 12 -h light (6:30 A.M. to 6:30 P.M.) and dark cycles. 17 $\alpha$-Ethinylestradiol (Sigma Chemical Co., St. Louis, MO) was dissolved in 1,2-propanediol ( $10 \mathrm{mg} / \mathrm{ml}$ ) and administered subcutaneously $(5 \mathrm{mg} / \mathrm{kg}$ body wt.) between 7:30 and 9:30 A.M. for 5 consecutive d. Control animals received equivalent amounts of 1,2-propanediol only. The two groups of animals were pair-fed ( 690 diet; Nafag, Gossau, Switzerland) in order to adjust the weight gain of control animals to the decreased food intake of EE-treated rats. All animals had free access to water. On day 6 the animals were killed by decapitation between 7:30 and 8:30 A.M.

Cholestatic parameters. The degree of EE-induced cholestasis was estimated by the determinations in serum of conjugated primary bile acids ( Becton-Dickinson, Orangeburg, NY), total cholesterol, total bilirubin, alkaline phosphatase, and leucine aminopeptidase (Department of Clinical Chemistry, University Hospital, Zürich). In addition, in some animals total bile flow was estimated by cannulation of the common bile duct (polyethylene 10 tubing) under pentobarbital $(65 \mathrm{mg} /$ $\mathrm{kg}$ body wt., i.p.) anesthesia. After $5 \mathrm{~min}$ bile was collected into tared

1. Abbreviations used in this paper: blLPM, basolateral (sinusoidal) liver plasma membrane vesicles; cLPM, canalicular liver plasma membrane vesicles; DIDS, 4,4'-diisothiocyano-2,2'-stilbenedisulfonic acid; DNP-SG, S-(2,4-dinitrophenyl) glutathione; EE, $17 \alpha$-ethinylestradiol. 
tubes during two 5-min periods and the mean bile flow estimated gravimetrically assuming a bile solution density of 1.0 .

Isolation of basolateral (blLPM) and canalicular (cLPM) liver plasma membrane subfractions. To be able to isolate highly purified blLPM and cLPM vesicles in parallel from control and EE-treated rats, a combination of two previously described subfractionation procedures $(11,12)$ was applied. All steps were done at $4^{\circ} \mathrm{C}$. Three livers $(25-40 \mathrm{~g})$ from each group of animals were homogenized in ice-cold 1 mM NaHCO${ }_{3}$ adjusted to $\mathrm{pH} 7.4$ with $\mathrm{HCl}$ and supplemented with 1 mM PMSF. After centrifugation at $1500 \mathrm{~g}$ for $15 \mathrm{~min}$ the "crude nuclear pellet" was resuspended in $30 \mathrm{ml}$ of $0.25 \mathrm{M} \mathrm{STM}(0.25 \mathrm{M}$ sucrose, $1 \mathrm{mM} \mathrm{MgCl}_{2}, 5 \mathrm{mM}$ Tris HCl, pH 7.4). Subsequently $120 \mathrm{ml}$ of $2.0 \mathrm{M}$ STM was added and the suspension adjusted to a density of $1.18 \mathrm{~g} / \mathrm{cm}^{3}$ $\left(1.42 \mathrm{M}, n_{\mathrm{D}}=1.4016\right)$ with $0.25 \mathrm{M}$ STM. $30-\mathrm{ml}$ aliquots of the sample were added to cellulose nitrate tubes and overlaid with $5 \mathrm{ml} 0.25 \mathrm{M}$ sucrose. After centrifugation for $60 \mathrm{~min}$ at $82,600 \mathrm{~g}$ (TST 28.38 rotor; Kontron Elektronik Gmbtd, Zürich, Switzerland), the membranes at the interface were collected with a plastic pasteur pipette, resuspended in $200 \mathrm{ml}$ ice-cold $1 \mathrm{mM} \mathrm{NaHCO}$, pH 7.4, and pelleted at $7500 \mathrm{~g}$ for $15 \mathrm{~min}$. These "mixed" liver plasma membranes were washed once more in $200 \mathrm{ml}$ of $1 \mathrm{mM} \mathrm{NaHCO}_{3}, \mathrm{pH} 7.4$, resedimented at $2700 \mathrm{~g}$ for $15 \mathrm{~min}$, and finally resuspended in $8.0 \mathrm{ml}$ of $0.25 \mathrm{M}$ sucrose. The subsequent separation of bILPM and CLPM was performed as described (12). Microsomes were isolated according to Meier et al. (13). The isolated membrane subfractions were resuspended in the appropriate buffer media by repeated passages through a 25 -gauge $(0.5 \mathrm{~mm})$ needle and the samples ( $>5 \mathrm{mg}$ protein $/ \mathrm{ml}$ ) stored in liquid nitrogen for up to $1 \mathrm{mo}$. without loss of transport activities.

Marker enzyme analysis. The degree of purification of blLPM and cLPM subfractions was estimated by the determination of marker enzyme activities such as $\mathrm{Na}^{+}, \mathrm{K}^{+}$ATPase (14) for basolateral plasma membranes; $\mathrm{Mg}^{++}$-ATPase (14), alkaline phosphatase (15) and leucine aminopeptidase (16) for canalicular plasma membranes; succinate cytochrome $c$ reductase (17) for mitochondria; NADPH cytochrome $c$ reductase (17) for microsomes; glucosaminidase (18) for lysosomes; and galactosyltransferase (19) for Golgi membranes.

Chemical analysis. Total protein was determined by a modification of the Lowry procedure (20) using bovine serum albumin as a standard. DNA was measured in homogenates according to Labarca and
Paigen (21). Membrane lipids were extracted (22) and individual phospholipid species separated by a modification (23) of the high-performance thin-layer chromatography (HPTLC) method of Schmitz et al. (24) using an automatic Camag ATS III sample applicator and a Camag TLC scanner II (Muttenz, Switzerland). Free and esterified cholesterol were determined by an enzymatic fluorometric assay as described (25).

Vesicle transport studies. Tracer uptake studies were performed by routine rapid filtration assays (26). The following transport activities were determined according to established procedures. In blLPM: $\mathrm{Na}^{+}$. gradient dependent uptake of [G- $\left.{ }^{3} \mathrm{H}\right]$ taurocholic acid $(2.1-6.6 \mathrm{Ci} /$ mmol; Du Pont-New England Nuclear, Boston, MA) (26). In cLPM: ATP-dependent uptake of $\left[{ }^{3} \mathrm{H}\right]$ taurocholate (27); 4,4-diisothiocyano2,2'-stilbenedisulfonic acid (DIDS)-sensitive electrogenic $\left[{ }^{3} \mathrm{H}\right]-$ taurocholate uptake in the presence of an intravesicular positive $\mathrm{K}^{+}$. diffusion potential (26); $\mathrm{HCO}_{3}^{-} /{ }^{35} \mathrm{SO}_{4}^{-}$-exchange (carrier-free $\left[{ }^{35} \mathrm{~S}\right]$ sulfate was obtained from DuPont-New England Nuclear, Boston, MA) (28); $\mathrm{Na}^{+}$-dependent uptake of $\left[2-{ }^{3} \mathrm{H}\right]$ adenosine $(27 \mathrm{Ci} / \mathrm{mmol}$; Amersham International, Amersham, United Kingdom) (29); $\mathrm{Na}^{+}-$ dependent uptake of $\left[2-{ }^{3} \mathrm{H}\right]$ glycine $(43 \mathrm{Ci} / \mathrm{mmol}$; DuPont-New England Nuclear) (30); and ATP-dependent uptake of the glutathioneconjugate S-(2,4-dinitrophenyl)-glutathione (DNP-SG) (31). The latter compound was synthesized in vitro from $\left[{ }^{14} \mathrm{C}(\mathrm{U})\right]-1$-chloro-2,4dinitrobenzene (CDNB; $10 \mathrm{mM} \mathrm{Ci} / \mathrm{mmol}$; Amersham International) as described (32).

In microsomes: Electrogenic $\left[{ }^{3} \mathrm{H}\right]$ taurocholate uptake in the presence of an intravesicular positive $\mathrm{K}^{+}$-diffusion potential (26). Further details and modifications of the indicated vesicle transport assays are given in the corresponding figure legends.

\section{Results}

The effects of EE treatment on various hepatobiliary parameters are summarized in Table I. While body wts were similar in control and treated animals, the liver weight increased in the treated group by $67 \%$. Since at the same time the DNA content per unit liver wt remained unaltered, these data confirm induction of liver growth by EE (parenchymal hyperplasia) (33).

Table I. Basic Parameters of EE-induced Cholestasis in Male Sprague-Dawley Rats

\begin{tabular}{|c|c|c|c|}
\hline & Day 0 & Day 5 & \\
\hline & (before treatment) & Controls / EE treated & \\
\hline Weights (g) & $(n=10)$ & $(n=11) /(n=11)$ & \\
\hline Body (body wt) & $230 \pm 20$ & $231 \pm 26 / 223 \pm 26$ & NS \\
\hline Liver & $11.0 \pm 1.4$ & $8.3 \pm 1.2 / 13.9 \pm 2.3$ & $P<0.001$ \\
\hline Bile flow & $(n=10)$ & $(n=10) /(n=11)$ & \\
\hline$(\mu \mathrm{l} / \mathrm{min} \times \mathrm{g}$ liver $)$ & $2.0 \pm 0.3$ & $2.1 \pm 0.4 / 0.7 \pm 0.2$ & $P<0.001$ \\
\hline$(\mu \mathrm{l} / \mathrm{min} \times 100 \mathrm{~g}$ body wt. $)$ & $9.5 \pm 1.5$ & $7.6 \pm 1.7 / 4.6 \pm 1.4$ & $P<0.001$ \\
\hline Serum parameters & $(n=10)$ & $(n=13) /(n=14)$ & \\
\hline Bile acids $(\mu \mathrm{mol} /$ liter $)$ & $3.4 \pm 1.7$ & $1.4 \pm 0.6 / 15.7 \pm 10.1$ & $P<0.001$ \\
\hline Cholesterol (mmol/liter) & $2.3 \pm 0.4$ & $1.9 \pm 0.6 / 0.6 \pm 0.2$ & $P<0.001$ \\
\hline Bilirubin $(\mu \mathrm{mol} /$ liter $)$ & $2.8 \pm 1.3$ & $3.0 \pm 1.3 / 3.6 \pm 1.9$ & NS \\
\hline Alkaline phosphatase (U/liter) & $316 \pm 78$ & $284 \pm 80 / 684 \pm 180$ & $P<0.001$ \\
\hline Leucineaminopeptidase (U/liter) & $50 \pm 8$ & $50 \pm 8 / 47 \pm 7$ & NS \\
\hline Liver homogenates & $(n=7)$ & $(n=13) /(n=13)$ & \\
\hline Protein (mg/g liver) & $124 \pm 4$ & $143 \pm 9 / 128 \pm 11$ & $P<0.001$ \\
\hline DNA (mg/g liver) & $2.5 \pm 0.4$ & $2.7 \pm 0.3 / 2.5 \pm 0.3$ & NS \\
\hline
\end{tabular}

All data represent the means \pm SD with the number of measurements given in parenthesis. Statistical analysis was performed by the unpaired Student's $t$ test. 
The cholestatic effect of EE was documented by a $40 \%$ decrease of total bile flow (expressed per unit body wt.), an 11-fold increase of the serum bile acid concentration, a 2.4-fold increase of serum alkaline phosphatase activity, and a $70 \%$ decrease in serum cholesterol (Table I). No significant changes were observed in serum bilirubin and leucineaminopeptidase activity.

The degree of purification and the enzyme recoveries in the blLPM and CLPM subfractions isolated from control and cholestatic rat livers are compared in Table II. No significant differences in membrane associated $\mathrm{Na}^{+} \mathrm{K}^{+}$-ATPase activity were found between homogenates and LPM subfractions of normal and cholestatic livers, respectively. Among the canalicular marker enzyme activities alkaline phosphatase was increased eightfold in "cholestatic" homogenates while leucineaminopeptidase did not change. Although protein and canalicular enzyme recoveries were $30-50 \%$ lower in cLPM isolated from cholestatic as compared with control livers, the lower enzyme activities were not due to an increased contamination of "cholestatic" cLPM with blLPM or with intracellular organelles as documented by similar enrichment factors for $\mathrm{Na}^{+} /$ $\mathrm{K}^{+}$-ATPase and for mitochondrial, endoplasmic reticulum, lysosomal, and Golgi marker enzyme activities (Table II). Thus, the cLPM subfraction could be purified to a similar degree from control and cholestatic rat livers.

With respect to the membrane lipid composition the greatest changes were found in blLPM vesicles, where EE treatment induced a fivefold increase in cholesteryl esters (control/cholestasis $=9 \pm 6 / 46 \pm 11 \mathrm{nmol}$ per $\mathrm{mg}$ protein; means $\pm \mathrm{SD} ; n$ $=8$ ), but no changes in either free cholesterol (control $/$ cholestasis $=0.17 \pm 0.03 / 0.18 \pm 0.05 \mu \mathrm{mol} / \mathrm{mg}$ protein $)$ or total phospholipids (control / cholestasis $=0.67 \pm 0.10 / 0.62 \pm 0.08 \mu \mathrm{mol} /$ mg protein). Among selective phospholipid species, phos- phatidylethanolamine (PE) decreased by $16 \%$ and phosphatidylserine (PS) increased by $22 \%$, while the relative contents of sphingomyelin (SPH), phosphatidylcholine (PC) and phosphatidylinositol (PI) remained unchanged. Thus, the ratios of $\mathrm{PE} / \mathrm{PC}$ decreased by $15 \%$ while the SPH/PC ratio was not significantly altered. In cLPM, EE administration had no significant effects on either cholesteryl esters (control/cholestasis $=19 \pm 11 / 24 \pm 8 \mathrm{nmol} / \mathrm{mg}$ protein), free cholesterol (control/ cholestasis $=0.59 \pm 0.06 / 0.63 \pm 0.08 \mu \mathrm{mol} / \mathrm{mg}$ protein $)$ or total phospholipids (control/cholestasis $=1.19 \pm 0.19 / 1.22 \pm 0.19$ $\mu \mathrm{mol} / \mathrm{mg}$ protein). Furthermore, only the relative content of PS increased slightly $(+18 \%)$, while the other polar membrane phospholipids (i.e., SPH, PC, PI, PE) and the derived PE/PC and $\mathrm{SPH} / \mathrm{PC}$ ratios remained unaffected. These data confirm that pharmacological doses of EE mainly affect the lipid composition of the sinusoidal plasma membrane of rat hepatocytes (7), whereas the canalicular membrane lipid composition is only minimally altered.

Fig. 1 illustrates the effects of EE treatment on $\mathrm{Na}^{+}$- and ATP-dependent taurocholate uptake in blLPM and cLPM vesicles, respectively. In blLPM vesicles $\mathrm{Na}^{+}$-dependent taurocholate uptake was decreased by approximately $40 \%$, thus confirming previous observations in intact hepatocytes (34). However, in "cholestatic" cLPM vesicles an even more dramatic decrease of over $60 \%$ was found for the recently described ( 27 , 35-37) ATP-dependent taurocholate uptake portion (Fig. 1 $B)$. No increase in ATP-dependent taurocholate uptake was observed in blLPM vesicles isolated in parallel from the same livers, indicating no redistribution of this bile salt transport system along the surface of hepatocytes as has been shown to occur for electrogenic taurocholate transport in obstructive cholestasis (38). Furthermore, the reduced canalicular ATP-dependent taurocholate uptake activity could be entirely ac-

Table II. Enzyme Enrichment and Percent Recovery in Basolateral (blLPM) and Canalicular (cLPM) Plasma Membrane Subfractions from Normal and Cholestatic Rat Liver*

\begin{tabular}{|c|c|c|c|c|c|c|}
\hline & \multirow{2}{*}{\multicolumn{2}{|c|}{$\begin{array}{l}\text { Homogenates } \\
\text { (specific activity) }\end{array}$}} & \multicolumn{4}{|c|}{ Relative enrichment ${ }^{\ddagger}$ and (\% Recovery) } \\
\hline & & & \multicolumn{2}{|c|}{ bILPM } & \multicolumn{2}{|c|}{ cLPM } \\
\hline & Control & Cholestasis & Control & Cholestasis & Control & Cholestasis \\
\hline \multirow[t]{2}{*}{$\mathrm{Na}^{+} / \mathrm{K}^{+}$-ATPase } & $1.2 \pm 0.3$ & $0.9 \pm 0.2$ & $30 \pm 4$ & $41 \pm 9$ & $3 \pm 2$ & $4 \pm 2$ \\
\hline & & & $(3 \%)$ & $(3 \%)$ & $(0.2 \%)$ & $(0.2 \%)$ \\
\hline \multirow[t]{2}{*}{$\mathrm{Mg}^{++}$-ATPase } & $4.3 \pm 0.3$ & $5.5 \pm 0.4^{\| \prime}$ & $5 \pm 1$ & $7 \pm 1^{11}$ & $48 \pm 9$ & $25 \pm 7^{11}$ \\
\hline & & & $(0.6 \%)$ & $(0.5 \%)$ & $(3 \%)$ & $(1.4 \%)$ \\
\hline \multirow[t]{2}{*}{ Alkaline phosphatase } & $0.2 \pm 0.1$ & $1.6 \pm 0.3^{\| \prime}$ & $12 \pm 3$ & $18 \pm 2^{11}$ & $101 \pm 9$ & $52 \pm 8^{11}$ \\
\hline & & & $(1 \%)$ & $(1 \%)$ & $(7 \%)$ & $(3 \%)$ \\
\hline \multirow[t]{2}{*}{ Leucineaminopeptidase } & $1.0 \pm 0.1$ & $1.0 \pm 0.1$ & $3 \pm 1$ & $5 \pm 1^{11}$ & $30 \pm 3$ & $19 \pm 5^{\| \prime}$ \\
\hline & & & $(0.4 \%)$ & $(0.4 \%)$ & $(2 \%)$ & $(1 \%)$ \\
\hline Succinate-cyt.c-reductase & $4.2 \pm 0.2$ & $4.4 \pm 0.4$ & $1.5 \pm 0.4$ & $0.9 \pm 0.2^{\| \prime}$ & $0.2 \pm 0.1$ & $0.1 \pm 0.1$ \\
\hline NADPH-cyt.c-reductase & $3.3 \pm 0.5$ & $2.8 \pm 0.4$ & $0.4 \pm 0.1$ & $0.5 \pm 0.1$ & $0.5 \pm 0.1$ & $0.7 \pm 0.2$ \\
\hline Glucosaminidase & $2.3 \pm 0.2$ & $2.5 \pm 0.2$ & $0.5 \pm 0.1$ & $0.6 \pm 0.1$ & $0.6 \pm 0.1$ & $0.9 \pm 0.2^{\prime \prime}$ \\
\hline Galactosyltransferase & $4.4 \pm 1.1$ & $4.6 \pm 1.1$ & $0.1 \pm 0.1$ & $0.1 \pm 0.1$ & $0.1 \pm 0.1$ & $0.1 \pm 0.1$ \\
\hline
\end{tabular}

\footnotetext{
* LPM subractions were isolated after 5-d treatment with either 1,2-propanediol (controls) or ethinylestradiol (cholestasis). Recoveries of membrane protein (mg/g liver) were as follows. BlLPM: controls $0.148 \pm 0.049$; cholestasis $0.094 \pm 0.041$ (no significant difference); $c L P M$ : controls $0.101 \pm 0.029$; cholestasis $0.070 \pm 0.035$ (no significant difference).

${ }^{\S}$ All data represent the means \pm SD of single measurements in 6 separate membrane preparations $(n=6)$. Specific activities are expressed as $\mu$ mol product formed $\cdot \mathrm{mg}^{-1}$ protein $\cdot \mathrm{h}^{-1}$ except for galactosyltransferase $\left(\mathrm{nmol} \cdot \mathrm{mg}^{-1} \cdot \mathrm{h}^{-1}\right)$.

${ }^{\ddagger}$ Relative enrichment is defined as the ratio of specific activity in the LPM to specific activity in the homogenate.

"Significantly different from controls $(P<0.05)$ as determined by the unpaired Student's $t$ test.
} 

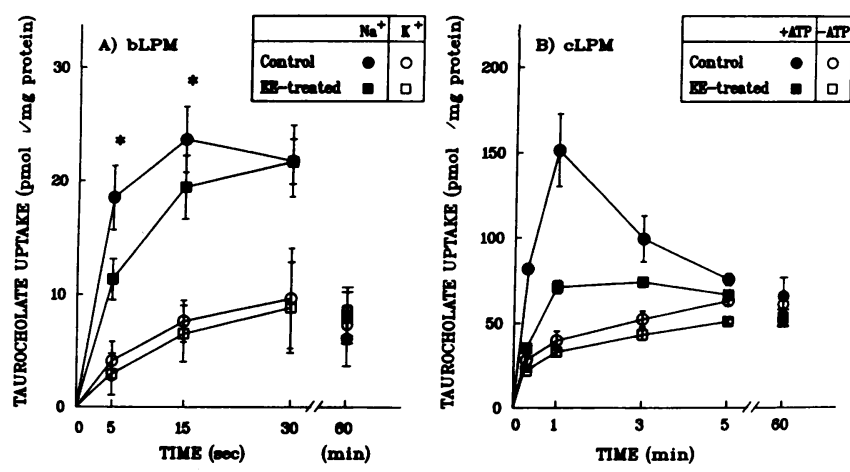

Figure 1. Effects of EE treatment of rats on $\mathrm{Na}^{+}$- and ATP-dependent uptake of taurocholate in blLPM and CLPM vesicles, respectively. $(A)$ blLPM vesicles were resuspended $(2.5 \mathrm{mg}$ protein $/ \mathrm{ml})$ in 0.25 $M$ sucrose, $0.2 \mathrm{mM} \mathrm{CaCl}, 20 \mathrm{mM}$ Hepes/Tris, $\mathrm{pH} 7.5$ and $\left[{ }^{3} \mathrm{H}\right]-$ taurocholate $(1.0 \mu \mathrm{M})$ uptake determined at $37^{\circ} \mathrm{C}$ in the presence of outside $100 \mathrm{mM} \mathrm{NaCl}(\bullet, \bullet)$ or $\mathrm{KCl}(\circ, \square), 50 \mathrm{mM}$ sucrose, 0.2 $\mathrm{mM} \mathrm{CaCl}, 5 \mathrm{mM} \mathrm{MgCl}_{2}$, and $20 \mathrm{mM}$ Hepes/Tris, pH 7.5, as described (26). ( $B)$ CLPM vesicles were resuspended $(2.5 \mathrm{mg}$ protein/ $\mathrm{ml}$ ) in $100 \mathrm{mM} \mathrm{KNO}_{3}, 50 \mathrm{mM}$ sucrose, $10 \mathrm{mM}$ Hepes/Tris, $\mathrm{pH}$ 7.5 , and $\left[{ }^{3} \mathrm{H}\right]$ taurocholate $(2.0 \mu \mathrm{M})$ uptake determined at $37^{\circ} \mathrm{C}$ in the presence $(\bullet, \square)$ and absence $(0, \square)$ of $5 \mathrm{mM}$ ATP (Tris salt) in the incubation medium consisting of (final concentrations) $100 \mathrm{mM}$ $\mathrm{KNO}_{3}, 50 \mathrm{mM}$ sucrose, $10 \mathrm{mM} \mathrm{MgNO}$ and $10 \mathrm{mM}$ Hepes/Tris, $\mathrm{pH} 7.5(27)$. In all incubations the vesicle protein concentration was adjusted to $50 \mu \mathrm{g} / 100 \mu \mathrm{l}$. All data represent the means \pm SD of triplicate determinations in three separate membrane isolations. *Significant differences between control and "cholestatic" blLPM vesicles $(P<0.01)$.

counted for by a decreased maximal taurocholate transport capacity as demonstrated by a reduction of $V_{\max }$ values from $721 \pm 50 \mathrm{pmol} / \mathrm{mg}$ protein $\times \min (\operatorname{mean} \pm \mathrm{SD})$ in control cLPM to $264 \pm 26 \mathrm{pmol} / \mathrm{mg}$ protein $\times$ min in "cholestatic" cLPM (Fig. 2). The corresponding $K_{\mathrm{m}}$ values did not change significantly (control/cholestasis $=3.6 \pm 0.7 \mu \mathrm{M} / 5.3 \pm 1.2$

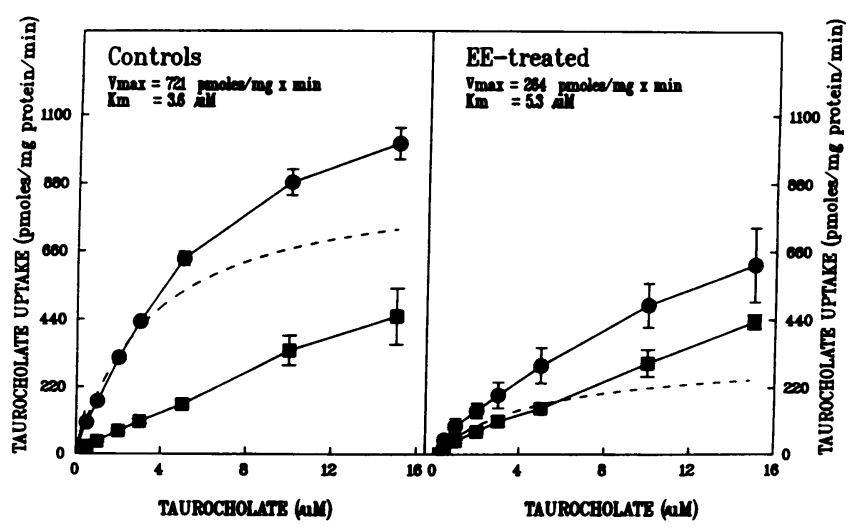

Figure 2. Kinetics of ATP-dependent taurocholate uptake in CLPM vesicles of controls (left) and EE-treated (right) rats. $\left[{ }^{3} \mathrm{H}\right]-$

Taurocholate uptake was determined at 20 seconds as described in Fig. $1 B$ in the presence of increasing extravesicular concentrations of unlabeled substrate. ATP-dependent uptake (dashed line) represents the difference between uptake values in the presence $(\bullet)$ and in the absence ( $\bullet$ ) of $5 \mathrm{mM}$ ATP. The data are the means \pm SD of triplicate determinations in 2 separate membrane preparations. Estimation of the kinetic parameters was performed by a computer-based nonlinear regression analysis. $\mu \mathrm{M})$. In addition, the apparent $K_{\mathrm{m}}$ values for ATP were around $0.5 \mathrm{mM}$ in both control (27) and "cholestatic" (data not shown) CLPM vesicles. Finally, estimation of liberated sialic acid in the absence and presence of $0.1 \%$ ( $\mathrm{vol} / \mathrm{vol}$ ) Triton $\mathrm{X}-100$ (39) revealed that both control and "cholestatic" cLPM vesicles were oriented inside out to $20-30 \%$ and right-side out to $70-80 \%$. These figures correspond to our previous observations in normal cLPM vesicles (40) and exclude an altered sidedness of the CLPM vesicles as a possible cause of the observed EE-induced canalicular membrane transport alterations. Thus, EE administration to rats primarily reduced the number of functional ATP-dependent bile salt carriers at the canalicular membrane, while the bile salt affinity of the remaining transport systems was virtually unaffected.

In contrast to the marked reduction of the ATP-dependent bile salt transport capacity, EE administration had only a minimal or even no effect on DIDS sensitive, electrogenic (intravesicular positive $\mathrm{K}^{+}$diffusion potential) taurocholate uptake (41) in cLPM and microsomes, respectively (Fig. 3). However, EE treatment also markedly reduced cLPM-associated ATPdependent transport of the glutathione conjugate DNP-SG (Fig. $4 \mathrm{~A}$ ), a cosubstrate of the canalicular multiorganic anion transporter (42), as well as of $\mathrm{Na}^{+}$-dependent adenosine uptake (29) (Fig. $4 C$ ). In contrast, and most surprisingly, canalicular $\mathrm{HCO}_{3}^{-} / \mathrm{SO}_{4}^{-}$exchange (28) and $\mathrm{Na}^{+}$-dependent glycine uptake (30) were markedly stimulated in CLPM vesicles isolated from cholestatic rat livers (Fig. $4 B, D$ ). These latter findings further argue against a higher contamination of "cholestatic" cLPM vesicles with intracellular membranes as a possible cause of the observed reductions in ATP-dependent organic anion transport activities. Thus, the data demonstrate that EEinduced cholestasis is associated with multiple inhibitory and stimulatory canalicular membrane transport alterations in rat liver.

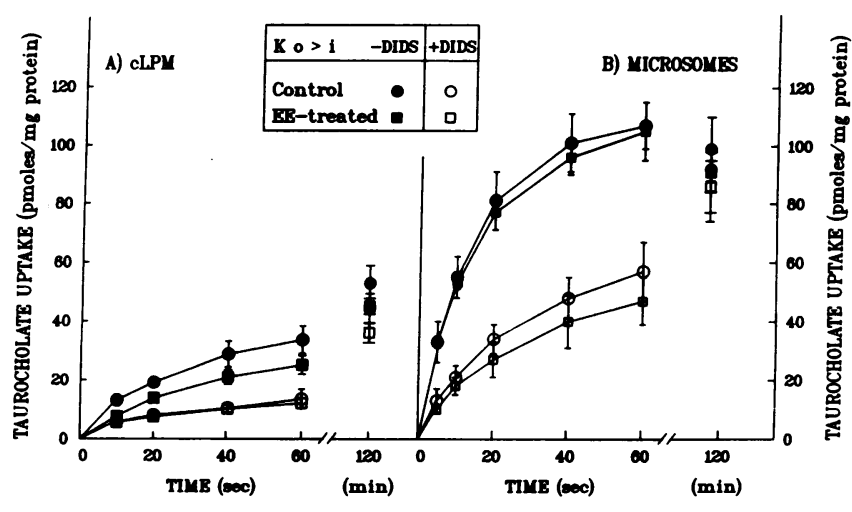

Figure 3. Electrogenic taurocholate uptake in CLPM vesicles (A) and microsomes (B) isolated from livers of control and EE-treated rats. cLPM vesicles and microsomes were resuspended $(3.0 \mathrm{mg}$ protein/ $\mathrm{ml}$ ) in $0.25 \mathrm{M}$ sucrose, $0.2 \mathrm{mM}$ Ca gluconate, and $20 \mathrm{mM}$ Hepes/ Tris, $\mathrm{pH}$ 7.4. All vesicles were preincubated with valinomycin ( 10 $\mu \mathrm{g} / \mathrm{mg}$ protein) for $5 \mathrm{~min}$ at room temperature. Uptake of $\left[{ }^{3} \mathrm{H}\right]-$ taurocholate $(2 \mu \mathrm{M})$ was performed at $25^{\circ} \mathrm{C}$ by incubating $20 \mu$ l vesicle suspension with $80 \mu$ incubation medium consisting of ( final concentrations) $100 \mathrm{mM}$ Kgluconate, $50 \mathrm{mM}$ sucrose, $0.2 \mathrm{mM}$ Cagluconate, $5 \mathrm{mM}$ Mggluconate, and $20 \mathrm{mM}$ Hepes/Tris, $\mathrm{pH} 7.4$, as described (26). Where indicated, $150 \mu \mathrm{M}$ of the anion transport inhibitor DIDS was also added. The data represent the means \pm SD of triplicate determinations in two separate membrane isolations. cLPM and microsomes were isolated in parallel from the same livers. 


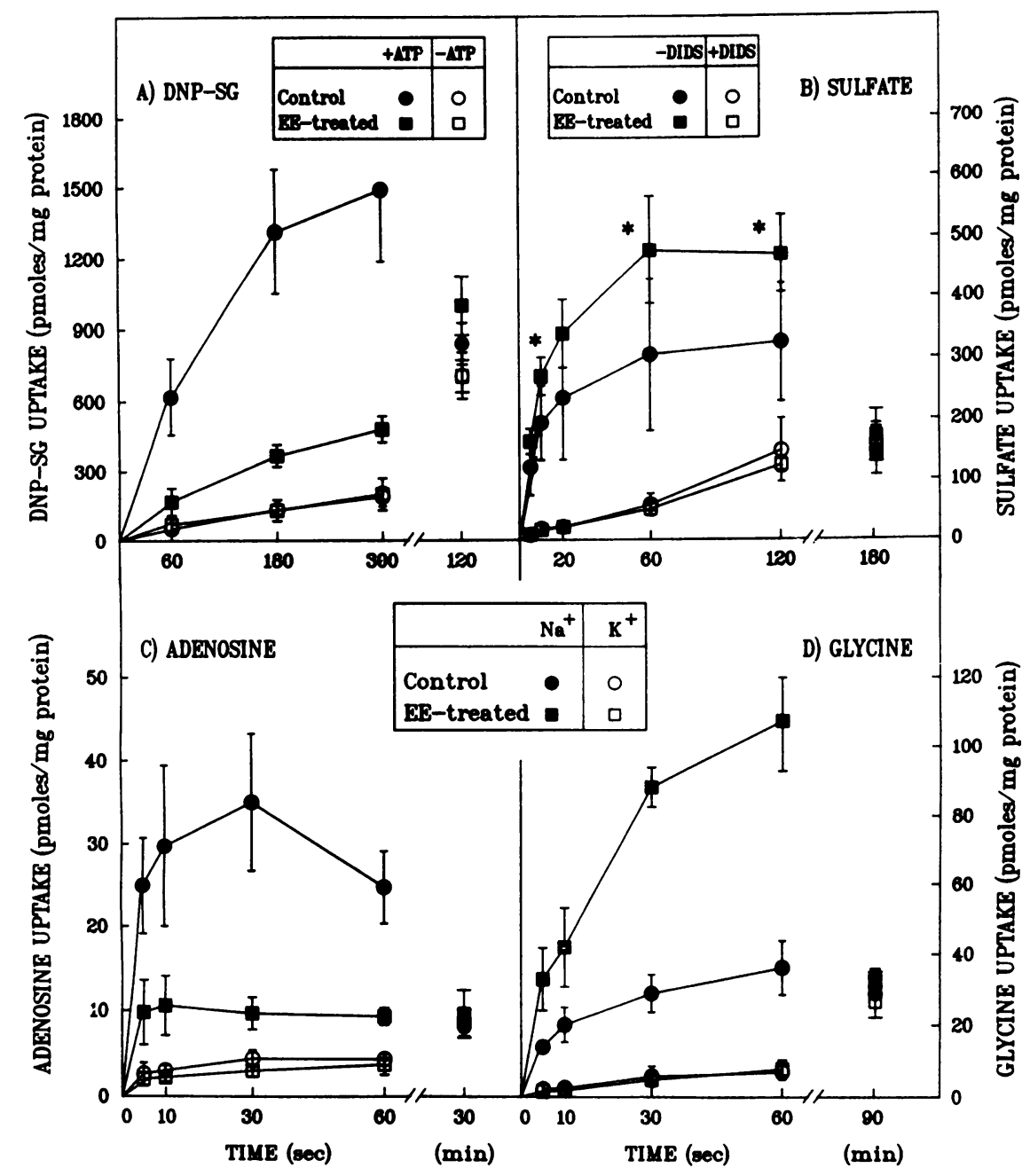

Figure 4. Effects of EE treatment of rats on four different non-bile-salt canalicular transport systems. $(A)$ cLPM vesicles were resuspended $(2.5 \mathrm{mg}$ Protein $/ \mathrm{ml})$ in $0.25 \mathrm{M}$ sucrose, $20 \mathrm{mM} \mathrm{MgCl}_{2}, 10 \mathrm{mM}$ Hepes/Tris, $\mathrm{pH}$ 7.4 , and preincubated with $100 \mu \mathrm{M}$ Acivicin (inhibition of $\gamma$-glutamyltranspeptidase) at $25^{\circ} \mathrm{C}$ for $30 \mathrm{~min}$. Uptake of ${ }^{14} \mathrm{C}$-labeled DNPSG was performed by incubating $20 \mu$ l vesicle suspension at $37^{\circ} \mathrm{C}$ in $80 \mu \mathrm{l}$ incubation medium containing ( final concentrations) 100 $\mu \mathrm{M}\left[{ }^{14} \mathrm{C}\right]$ DNP-SG, $0.25 \mathrm{M}$ sucrose, $20 \mathrm{mM}$ $\mathrm{MgCl}_{2}, 30 \mathrm{mM}$ creatine phosphate, 200 units/ $\mathrm{ml}$ creatine kinase, $10 \mathrm{mM}$ Tris $/ \mathrm{HCl}, \mathrm{pH} 7.4$, with $(\bullet, \bullet)$ or without $(0, \square) 1 \mathrm{mM} \operatorname{ATP}(31)$. $(B) \mathrm{cLPM}$ vesicles were resuspended $(6.0 \mathrm{mg}$ protein $/ \mathrm{ml}$ ) in $130 \mathrm{mM}$ sucrose, $50 \mathrm{mM}$ $\mathrm{KHCO}_{3}, 50 \mathrm{mM}$ Kgluconate, $0.4 \mathrm{mM}$ Cagluconate, $10 \mathrm{mM}$ Mggluconate, $35 \mathrm{mM}$ Hepes/ Tris, $\mathrm{pH}$ 8.0. The vesicles were pretreated with valinomycin ( $10 \mu \mathrm{g} / \mathrm{mg}$ protein $)$ and $\left[{ }^{35} \mathrm{~S}\right]-$ sulfate $\left(2 \times 10^{7} \mathrm{dpm} / \mathrm{ml}\right)$ uptake determined by incubating $10 \mu \mathrm{l}$ vesicle suspension at $25^{\circ} \mathrm{C}$ in $90 \mu \mathrm{l}$ of incubation medium containing 70 $\mathrm{mM}$ sucrose, $100 \mathrm{mM}$ Kgluconate, $0.4 \mathrm{mM}$ Cagluconate, $10 \mathrm{mM}$ Mggluconate, $70 \mathrm{mM}$ Hepes/Tris, pH 8.0 without $(\bullet, \bullet)$ and with $(\circ, \square) 0.5 \mathrm{mM}$ DIDS (28). The outside sulfate concentration was adjusted to $100 \mu \mathrm{M}$ with neutral $\mathrm{K}_{2} \mathrm{SO}_{4} \cdot\left({ }^{*}\right)$ significantly different from controls $(P<0.01) .(C, D)$ The vesicles were resuspended ( $2.5 \mathrm{mg}$ protein $/ \mathrm{ml}$ ) in $0.25 \mathrm{M}$ sucrose, $0.2 \mathrm{mM} \mathrm{CaCl}_{2}, 20 \mathrm{mM}$ Hepes/Tris, pH 7.4. $\left[{ }^{3} \mathrm{H}\right]$ Adenosine $(1 \mu \mathrm{M})$ and $\left[{ }^{3} \mathrm{H}\right]-$ glycine $(10 \mu \mathrm{M})$ uptakes were determined at $25^{\circ} \mathrm{C}$ by incubating $20 \mu \mathrm{l}$ membrane suspensions in $80 \mu \mathrm{l}$ of incubation medium consisting of (final concentrations) $100 \mathrm{mM} \mathrm{NaCl}(\bullet$, -) or $100 \mathrm{mM} \mathrm{KCl}(\circ, \square), 50 \mathrm{mM}$ sucrose,

$0.2 \mathrm{mM} \mathrm{CaCl}_{2}, 5 \mathrm{mM} \mathrm{MgCl}_{2}$ and $20 \mathrm{mM}$ Hepes/Tris, $\mathrm{pH} 7.4(29,30)$. All data represent the means $\pm \mathrm{SD}$ of triplicate determinations in two separate membrane preparations.

\section{Discussion}

This study demonstrates that EE administration to male rats causes marked alterations of various transport activities in cLPM vesicles isolated from the cholestatic livers. The documented canalicular transport alterations include a $63 \%$ decrease of the ATP-dependent bile salt transport capacity (Fig. 2), a similar decrease of initial ATP-dependent dinitrophenylglutathione and of $\mathrm{Na}^{+}$-dependent adenosine uptake rates (Fig. 4) as well as a marked increase of $\mathrm{HCO}_{3}^{-} / \mathrm{SO}_{4}^{=}$-exchange and of $\mathrm{Na}^{+}$-dependent glycine uptake activities (Fig. 4). These functional transport alterations occurred without significant changes in the sidedness or in the lipid composition of the isolated canalicular membrane vesicles. Furthermore, although in blLPM vesicles similar changes in cholesteryl esters and polar phospholipids were found as previously described (7), the activity of basolateral $\mathrm{Na}^{+} / \mathrm{K}^{+}$-ATPase activity was not significantly altered (Table II), thus supporting the view that an impaired sinusoidal $\mathrm{Na}^{+} / \mathrm{K}^{+}$-ion pumping cannot account for the EE-induced decrease in canalicular bile flow and bile salt secretion $(5,6,43,44)$. Most likely the same is also true for the observed $40 \%$ decrease in $\mathrm{Na}^{+}$-dependent taurocho- late uptake into blLPM vesicles (Fig. 1), since for conjugated bile salts the sinusoidal uptake capacity normally exceeds the maximal canalicular secretory capacity about sixfold (45). Thus, our findings do not support the concept that selective alterations in the sinusoidal surface of hepatocytes play a unique role in the pathogenesis of EE-induced intrahepatic cholestasis $(7,10)$. Rather, our data support, but do not yet prove, the alternative possibility that assigns the primary cause(s) of EE-induced bile secretory failure to the canalicular membrane domain of hepatocytes $(2,9,46,47)$.

Most importantly, this study indicates that a decreased canalicular ATP-dependent bile salt transport capacity is primarily responsible for the EE-induced impairment of bile salt secretion in intact liver $(1-3,44,46)$. Consequently, this recently described canalicular bile salt transporter $(27,35-37)$ appears to play an important physiological role in the maintenance and regulation of bile salt dependent bile flow in normal liver. Although its exact relationship to the previously characterized potential sensitive bile salt secretory pathway $(26,39,48)$ is not yet known, evidence has recently been provided that both electrogenic and ATP-dependent taurocholate transport might be mediated by the same or closely related canalicular transport 
protein(s) (36). Since electrogenic taurocholate uptake was higher in microsomes than in CLPM vesicles and not or only minimally affected by EE administration (Fig. 3), this study indicates instead that both transport activities are mediated by different transport systems. Although this assumption as well as the exact cause of the EE-induced decrease in the canalicular ATP-dependent bile salt transport capacity require further investigation, the data strongly indicate that $E E$ administration reduces the number of functionally active ATP-dependent bile salt carriers in the canalicular membrane either by reducing their biosynthesis and insertion into or by increasing their degradation and retrieval from the canalicular membrane (48).

Similar to impaired bile salt secretion, the estrogen-induced hepatic excretory failure for other organic anions such as bilirubin and bromosulfophthalein (BSP) (1-3) can also be explained by a canalicular transport defect as evidenced by the decreased ATP-dependent transport activity for DNP-SG (Fig. 4 ), which represents a typical cosubstrate (31) of the canalicular multiorganic anion transporter (42). Interestingly, the EEinduced decrease of both ATP-dependent transport activities (for taurocholate and DNP-SG) was associated with a similar decrease in $\mathrm{Na}^{+}$-dependent uptake of adenosine into cLPM vesicles (Fig. 4). Since ATP-dependent transport has been shown to be mediated by the inside-out-oriented portion of cLPM vesicles $(35,39)$, while $\mathrm{Na}^{+}$-dependent adenosine uptake relates to the right-side-out-oriented cLPM vesicles (29), the latter transport system is thought to be involved in the reuptake of nucleosides from the canalicular lumen back into the cells. Thus, a close functional interdependence between the intracanalicular availability of nucleotides, their degradation by the canalicular ecto-ATPase (49), and the reuptake of their degradation products (nucleosides) appears to exist in normal liver.

Finally, our data demonstrate that EE treatment of rats not only decreases, but also can stimulate certain canalicular transport activities (Fig. 4). The pathophysiologic significance of the increased $\mathrm{HCO}_{3}^{-} / \mathrm{SO}_{4}^{-}$-exchange activity cannot be easily judged since the physiological role of this anion exchange system is not yet known $(28,50)$. However, the increased $\mathrm{Na}^{+}$dependent glycine uptake activity is reminiscent of the previously reported increase in basolateral alanine uptake in midpregnant rats $(51)$. This latter observation was supported in the present study by the finding of a fivefold increase in $\mathrm{Na}^{+}$. dependent alanine uptake into blLPM vesicles isolated from EE-treated as compared with control rats (data not shown). Thus, increased reabsorption of amino acids from both portal blood plasma and the canalicular lumen $(30,52)$ represents a further compensatory mechanism for the estrogen-induced increase in the hepatocellular protein and amino acid turnover and metabolism (51). Since glycine represents a degradation product of reduced glutathione (GSH), the canalicular secretion and intrabiliary hydrolysis of which have been shown to significantly contribute to the generation of canalicular bile salt independent bile flow ( 53 ), increased canalicular reabsorption of amino acid constituents of GSH could also significantly contribute to the well-described decrease in the bile salt independent fraction of bile flow in estrogen-induced cholestasis (1-3, $43,46)$.

In conclusion, this study provides the first direct evidence that estrogen-induced cholestasis is associated with multiple canalicular in addition to the previously demonstrated sinusoidal membrane transport alterations in rat liver. Although the exact molecular mechanisms of the observed canalicular membrane transport alterations require further investigations, the findings suggest that most EE-related bile secretory defects might primarily originate from inhibition of excretory and stimulation of reabsorptive mechanisms at the canalicular pole of hepatocytes.

\section{Acknowledgments}

We thank Prof. Dr. H. Hauser from the Swiss Federal Institute of Technology, Zurich, for his continuous support and many useful suggestions. This work is dedicated to Professor Dr. G. Baumgartner, Munich, FRG, on the occasion of his 60th birthday.

This study was supported by Swiss National Science Foundation grants 32-9370.87, 32-29878.90 (to P. J. Meier) and 31-26334.89 (to B. Stieger).

\section{References}

1. Schreiber, A. J., and F. R. Simon. 1983. Estrogen-induced cholestasis: Clues to pathogenesis and treatment. Hepatology. 3:607-613.

2. Kreek, M. J. 1987. Female sex steroids and cholestasis. Semin. Liver Dis. 7:8-22.

3. Vore, M. 1987. Estrogen cholestasis. Membranes, metabolites, or receptors? Gastroenterology. 93:643-649.

4. Jaeschke, H., E. Trummer, and H. Krell. 1987. Increase in biliary permeability subsequent to intrahepatic cholestasis by estradiol valerate in rats. Gastroenterology. 93:533-538.

5. Smith, D. J., and E. R. Gordon. 1988. Role of liver plasma membrane fluidity in the pathogenesis of estrogen-induced cholestasis. J. Lab. Clin. Med. 112:679-685.

6. Boelsterli, U. A., G. Rakhit, and T. Balazs. 1983. Modulation by S-adenosyl-L-methionine of hepatic $\mathrm{Na}^{+}, \mathrm{K}^{+}$-ATPase, membrane fluidity, and bile flow in rats with ethinyl estradiol-induced cholestasis. Hepatology. 3:12-17.

7. Rosario, J., E. Sutherland, L. Zaccaro, and F. R. Simon. 1988. Ethinylestradiol administration selectively alters liver sinusoidal membrane lipid fluidity and protein composition. Biochemistry. 27:3939-3946.

8. Isaacson, Y., and D. H. Van Thiel. 1988. Increased membrane fluidity and cholestasis: Associated but not linked consequences of estrogen treatment. $J$. Lab. Clin. Med. 112:663-666.

9. Tarao, K., E. J. Olinger, J. D. Ostrow, and W. F. Balistreri. 1982. Impaired bile acid efflux from hepatocytes isolated from the liver of rats with cholestasis. Am. J. Physiol. 243:G253-G258.

10. Reichen, J., and F. R. Simon. 1988. Cholestasis. In The Liver: Biology and Pathobiology. I. M. Arias, W. B. Jakoby, H. Popper, D. Schachter, and D. A. Shafritz, editors. Raven Press, New York. 1105-1124.

11. Hubbard, A. L., D. A. Wall, and A. Ma. 1983. Isolation of rat hepatocyte plasma membranes. I. Presence of the three major domains. J. Cell Biol. 96:217229 .

12. Meier, P. J., E. S. Sztul, A. Reuben, and J. L. Boyer. 1984. Structural and functional polarity of canalicular and basolateral plasma membrane vesicles isolated in high yield from rat liver. J. Cell Biol. 98:991-1000.

13. Meier, P. J., M. A. Spycher, and U. A. Meyer. 1981. Isolation and characterization of rough endoplasmic reticulum associated with mitochondria from normal rat liver. Biochim. Biophys. Acta. 646:283-297.

14. Scharschmidt, B. F., E. B. Keeffe, N. M. Blankenship, and R. K. Ockner 1979. Validation of a recording spectrophotometric method for measurement of membrane-associated $\mathrm{Mg}^{++}$and $\mathrm{Na}^{+}, \mathrm{K}^{+}-\mathrm{ATPase}$ activity. J. Lab. Clin. Med. 93:790-799.

15. Pekarthy, J. M., J. Short, A. I. Lansing, and I. Liebermann. 1972. Function and control of liver alkaline phosphatase. J. Biol. Chem. 247:1767-1774.

16. Haase, W., A. Schaefer, H. Murer, and R. Kinne. 1978. Studies on the orientation of brush border membrane vesicles. Biochem. J. 172:57-62.

17. Sottocasa, G. L., B. Kuylenstierna, L. Ernster, and A. Bergstrand. 1967. An electron-transport system associated with the outer membrane of liver mitochondria. A biochemical and morphological study. J. Cell Biol. 32:415-438.

18. Scalera, V., C. Storelli, C. Storelli-Joss, W. Haase, and H. Murer. 1980. A simple and fast method for the isolation of basolateral plasma membranes from rat small intestinal epithelial cells. Biochem. J. 186:177-181.

19. Verdon, B., and E. G. Berger. 1983. Galactosyltransferase. In Methods of Enzymatic Analysis. H. U. Bergmeyer, editor. Verlag Chemie, Weinheim, FRG. 374-381. 
20. Bensadou, A., and D. Weinstein. 1976. Assay of proteins in the presence of interfering materials. Anal. Biochem. 70:241-250.

21. Labarca, C., and K. Paigen. 1980. A simple, rapid and sensitive DNA assay procedure. Anal. Biochem. 102:344-352.

22. Bligh, E. G., and W. J. Dyer. 1959. A rapid method of total lipid extraction and purification. Can. J. Biochem. Physiol. 37:911-917.

23. Kraehenbühl, S., P. J. Meier, and J. Reichen. 1989. Membrane function and lipid composition are not altered in liver plasma membrane vesicles from cirrhotic rats. J. Hepatol. (Amst.). 9:1-9.

24. Schmitz, G., G. Assmann, and D. E. Bowyer. 1984. A quantitative densitometric method for the rapid separation and quantification of the major tissue and lipoprotein lipids by high-performance thin-layer chromatography. J. Chroma togr. 307:65-79.

25. Heider, J. G., and R. L. Boyett. 1978. The picomole determination of free and total cholesterol in cells in culture. J. Lipid Res. 19:514-518.

26. Boyer, J. L., and P. J. Meier. 1990. Characterizing mechanisms of hepatic bile acid transport utilizing isolated membrane vesicles. Methods Enzymol. 192:517-533

27. Stieger, B., B. O'Neill, and P. J. Meier. 1992. ATP-dependent bile salt transport in canalicular rat liver plasma membrane vesicles. Biochem. J. 284:6774

28. Meier, P. J., J. Valantinas, G. Hugentobler, and I. Rahm. 1987. Bicarbonate sulfate exchange in canalicular rat liver plasma membrane vesicles. $\mathrm{Am}$. J Physiol. 253:G461-G468.

29. Moseley, R. H., S. Jarose, and P. Permoad. 1991. Adenosine transport in rat liver plasma membrane vesicles. Am. J. Physiol. 261:G716-G722.

30. Moseley, R. H., N. Ballatori, and S. M. Murphy. 1988. $\mathrm{Na}^{+}$-glycine cotransport in canalicular liver plasma membrane vesicles. Am. J. Physiol. 255:G253-G259.

31. Akerboom, T. P. M., V. Narayanaswami, M. Kunst, and H. Sies. 1991 ATP-dependent S-(2,4-dinitrophenyl) glutathione transport in canalicula plasma membrane vesicles from rat liver. J. Biol. Chem. 266:13147-13152.

32. Ishikawa, T. 1989. ATP/ $\mathbf{M g}^{2+}$-dependent cardiac transport system for glutathione S-conjugates. A study using rat heart sarcolemma vesicles. J. Biol. Chem. 264:17343-17348.

33. Ochs, H., B. Düsterberg, P. Günzel, and R. Schulte-Hermann. 1986 Effect of tumor promoting contraceptive steroids on growth and drug metabolizing enzymes in rat liver. Cancer Res. 46:1224-1232.

34. Berr, F., F. R. Simon, and J. Reichen. 1984. Ethinylestradiol impairs bile salt uptake and Na-K pump function of rat hepatocytes. Am. J. Physiol 247:G437-G443.

35. Nishida, T., Z. Gatmaitan, M. Che, and I. M. Arias. 1991. Rat live canalicular membrane vesicles contain an ATP-dependent bile acid transport system. Proc. Natl. Acad. Sci. USA. 88:6590-6594.

36. Müller, M., T. Ishikawa, U. Berger, C. Klünemann, L. Lucka, A. Schreyer, C. Kannicht, W. Reutter, G. Kurz, and D. Keppler. 1991. ATP-dependent transport of taurocholate across the hepatocyte canalicular membrane mediated by a 110-kDa glycoprotein binding ATP and bile salt. J. Biol. Chem. 266:1892018926.
37. Adachi, Y, H. Kobayashi, Y. Kurumi, M. Shouji, M. Kitano, and T. Yamamoto. 1991. ATP-dependent taurocholate by rat liver canalicular membrane vesicles. Hepatology. 14:655-659.

38. Fricker, G., L. Landmann, and P. J. Meier. 1989. Extrahepatic obstructive cholestasis reverses the bile salt secretory polarity of rat hepatocytes. J. Clin. Invest. 84:876-885.

39. Ishikawa, T., M. Müller, C. Klünemann, T. Schaub, and D. Keppler. 1990. ATP-dependent primary active transport of cysteinyl leukotrienes across liver canalicular membrane. J. Biol. Chem. 265:19279-19286.

40. Meier, P. J., A. Meier-Abt, C. Barrett, and J. L. Boyer. 1984. Mechanisms of taurocholate transport in canalicular and basolateral rat liver plasma membrane vesicles. J. Biol. Chem. 259:10614-10622.

41. Ruetz, S., G. Fricker, G. Hugentobler, K. Winterhalter, G. Kurz, and P. J. Meier. 1987. Isolation and characterization of the putative canalicular bile salt transport system of rat liver. J. Biol. Chem. 262:11324-11330.

42. Kitamura, T., P. Jansen, C. Hardenbrook, Y. Kamimoto, Z. Gatmaitan, and I. M. Arias. 1990. Defective ATP-dependent bile canalicular transport of organic anions in mutant ( $\mathrm{TR}^{-}$) rats with conjugated hyperbilirubinemia. Proc. Natl. Acad. Sci. USA. 87:3557-3561.

43. Keeffe, E. B., B. F. Scharschmidt, N. M. Blankenship, and R. K. Ockner. 1979. Studies of relationships among bile flow, liver plasma membrane $\mathrm{NaK}$ ATPase, and membrane microviscosity in the rat. J. Clin. Invest. 64:1590-1598.

44. Simon, F. R., M. Gonzalez, E. Sutherland, L. Accatino, and R. A. Davis. 1980. Reversal of ethinyl estradiol-induced bile secretory failure with Triton WR-

1339. J. Clin. Invest. 65:851-860.

45. Reichen, J., and G. Paumgartner. 1976. Relationship between bile flow and $\mathrm{Na}^{+}, \mathrm{K}^{+}$-adenosinetriphosphatase in liver plasma membranes enriched in bile canaliculi. Am. J. Physiol. 231:734-742.

46. Gumucio, J. J., and V. D. Vladivieso. 1971. Studies on the mechanism of the ethinyl-estradiol impairment of bile flow and bile salt extraction in the rat. Gastroenterology. 61:339-344.

47. Simon, F. R., and I. M. Arias. 1973. Alteration of bile canalicular enzymes in cholestasis. A possible cause of bile secretory failure. J. Clin. Invest. 52:765775 .

48. Nathanson, M. H., and J. L. Boyer. 1991. Mechanisms and regulation of bile secretion. Hepatology. 14:551-566.

49. Lin, S. H. 1989. Localization of the ecto-ATPase (ecto-nucleotidase) in the rat hepatocyte plasma membrane. J. Biol. Chem. 264:14403-14407.

50. Boyer, J. L., J. Graf, and P. J. Meier. 1992. Hepatic transport systems regulating $\mathrm{pH}_{\mathrm{i}}$, cell volume, and bile secretion. Annu. Rev. Physiol. 54:415-438.

51. Pastor-Anglada, M., X. Remesar, and G. Bowdel. 1987. Alanine uptake by liver at midpregnancy of rats. Am. J. Physiol. 252:E408-E413.

52. Ballatori, N., R. Jacob, C. Barrett, and J. L. Boyer. 1988. Biliary catabolism of glutathione and differential reabsorption of its amino acid constituents. Am. J. Physiol. 254:G1-G7.

53. Ballatori, N., and A. T. Truong. 1988. Relation between biliary glutathione excretion and bile acid independent bile flow. Am. J. Physiol. 256:G482G490. 